\title{
Midbrain dopaminergic neurons generate calcium and sodium currents and release dopamine in the striatum of pups
}

\author{
Diana C. Ferrari ${ }^{1,2}$, Baya J. Mdzomba ${ }^{1,2+}$, Nathalie Dehorter ${ }^{1,2+}$, Catherine Lopez ${ }^{1,2}$, \\ François J. Michel ${ }^{1,2}$, Frédéric Libersat ${ }^{1,2+}$ and Constance Hammond ${ }^{1,2 *}$ \\ 1 Institut National de la Recherche Médicale et de la Santé Inserm, INMED UMR 901, Marseille, France \\ ${ }^{2}$ Faculté des Sciences, Aix Marseille Université, Marseille, France
}

\section{Edited by:}

Enrico Cherubini, International

School for Advanced Studies, Italy

Reviewed by:

Nicola B. Mercuri, University of

Rome, Italy

Kazuto Kobayashi, Fukushima

Medical University, Japan

*Correspondence:

Constance Hammond, Institut

National de la Recherche Médicale

et de la Santé Inserm, INMED UMR

901, 163 route de Luminy, BP13,

13273 Marseille Cédex 9, France.

e-mail: hammond@inmed.

univ-mrs.fr

${ }^{\dagger}$ Present address:

Baya J. Mdzomba, Bernstein Focus

Neurotechnology and

Johann-Friedrich-Blumenbach

Institute for Zoology and

Anthropology, University of

Göttingen, D-37075 Göttingen,

Germany.

Nathalie Dehorter, Instituto de

Neurociencias de Alicante CSIC,

Universidad Miguel Hernández

03550 Alicante, España.

Frédéric Libersat, Department of

Life Sciences, Ben Gurion

University, POB 653, Beer Sheva,

Israel.
Midbrain dopaminergic neurons (mDA neurons) are essential for the control of diverse motor and cognitive behaviors. However, our understanding of the activity of immature mDA neurons is rudimentary. Rodent mDA neurons migrate and differentiate early in embryonic life and dopaminergic axons enter the striatum and contact striatal neurons a few days before birth, but when these are functional is not known. Here, we recorded $\mathrm{Ca}^{2+}$ transients and $\mathrm{Na}^{+}$spikes from embryonic (E16-E18) and early postnatal (P0-P7) mDA neurons with dynamic two-photon imaging and patch clamp techniques in slices from tyrosine hydroxylase-GFP mice, and measured evoked dopamine release in the striatum with amperometry. We show that half of identified E16-P0 mDA neurons spontaneously generate non-synaptic, intrinsically driven $\mathrm{Ca}^{2+}$ spikes and $\mathrm{Ca}^{2+}$ plateaus mediated by $\mathrm{N}$ - and L-type voltage-gated $\mathrm{Ca}^{2+}$ channels. Starting from E18-P0, half of the $\mathrm{mDA}$ neurons also reliably generate overshooting $\mathrm{Na}^{+}$spikes with an abrupt maturation at birth $(P 0=E 19)$. At that stage $(E 18-P 0)$, dopaminergic terminals release dopamine in a calcium-dependent manner in the striatum in response to local stimulation. This suggests that mouse striatal dopaminergic synapses are functional at birth.

Keywords: development, basal ganglia, substantia nigra, dopamine, immature activity, patch clamp, two-photons imaging

\section{INTRODUCTION}

Dopaminergic neurons located in the ventral midbrain (mDA) give rise to the mesostriatal, mesocortical, and mesolimbic pathways. The vast majority (around $80 \%$ ) of $\mathrm{mDA}$ neurons are born at E12 in rats (Gates et al., 2006) in the ventral aqueductal ventricular zone. Then they become post-mitotic, enter into a differentiation and specification program, and migrate ventrolaterally and rostrally along radial glia processes to their final location in the tegmental mantle to form the A8-A10 subgroups (Kawano et al., 1995; Hall et al., 2003). They start extending processes at E13 in rats (Moon and Herkenham, 1984; van der Kooy and Fishell, 1987; Voorn et al., 1988; Fishell and van der Kooy, 1989; Gates et al., 2006; van den Heuvel and Pasterkamp, 2008). Tyrosine hydroxylase $(\mathrm{TH})$, the rate limiting enzyme for catecholamine synthesis, is localized in the growing tips of axons, and $\mathrm{TH}$-positive $\left(\mathrm{TH}^{+}\right)$axonal processes are first detected within the ventrolateral developing striatum at E14.5 where they form a few specialized contacts with striatal somas or near the origin of dendrites (Specht et al., 1981a,b). Accordingly, dopamine is first detected in the forebrain at E13 in mice and DA binding sites (D1-like and D2-like) are present in the embryonic rodent neostriatum from E14 (Ohtani et al., 2003; Goffin et al., 2010). In addition, antidromic activation of rat substantia nigra compacta (SNc, A9) neurons from the striatum at $\mathrm{P} 0$ in vivo confirms the presence of the nigro-striatal DA pathway at birth (Tepper et al., 1990; Trent et al., 1991). Collectively, these studies suggest that the nigro-striatal system is ready to operate at late embryonic stages but the functionality of this pathway and whether it does release dopamine has not been established. This information is important as it conditions our understanding of the operation and role of this system during development.

Here, we combined electrophysiological and imaging studies to describe the developmental sequences of neuronal and network activity, with dopamine release experiments to detect the 
earliest evoked release of DA in the striatum. Since perinatal mDA neurons cannot be always identified by their adult electrophysiological characteristics (Washio et al., 1999) or their localization, we performed our experiments in brain slices from TH-GFP mice (Sawamoto et al., 2001). Our results show that at birth (P0), a subpopulation $(20 \%)$ of mDA neurons spontaneously generate full amplitude $\mathrm{Na}^{+}$spikes, in an intrinsically drive tonic or bursting pattern. At the same age, dopaminergic fibers release dopamine in a calcium-dependent manner in the striatum upon stimulation. Therefore, this suggests that mouse striatal dopaminergic synapses are functional at birth.

\section{METHODS \\ ANIMALS AND SLICES}

We performed experiments on wild-type or TH-GFP C57BL/6 mice (Matsushita et al., 2002) maintained in our institutional animal facility. Female mice were examined for the presence of a vaginal plug the morning after mating. The day of plug discovery was designated as embryonic day 0 (E0). Experiments were performed on mice of either sex. We removed E16 and E18 mice from deeply anesthetized dams [subcutaneous injection of a mixture of xylazine (Rompun 2\%; used at $0.05 \%$ ) and ketamine (Imalgene 1000 used at $50 \mathrm{~g} / \mathrm{L}$ ) volume injected: $0.1 \mathrm{~mL} / 10 \mathrm{~g}$ ]. The embryos were kept in an ice-cold oxygenated solution containing (in $\mathrm{mM}$ ): 110 choline, $2.5 \mathrm{KCl}, 1.25 \mathrm{NaH}_{2} \mathrm{PO}_{4}, 7 \mathrm{MgCl}_{2}$, $0.5 \mathrm{CaCl}_{2}, 25 \mathrm{NaHCO}_{3}, 7$ glucose. Postnatal mice (P0-P7) were killed by decapitation under isofluorane anaesthesia. Coronal and parasagittal slices $(400 \mu \mathrm{m}$ thick) were cut in the ice-cold oxygenated choline solution using a vibratome (VT1200 Leica Microsystems Germany). During the recovery period, slices were placed at room temperature with standard artificial cerebrospinal fluid (ACSF) saturated with $95 \% \mathrm{O}_{2} / 5 \% \mathrm{CO}_{2}$ and containing the following (in mM): $126 \mathrm{NaCl}, 3.5 \mathrm{KCl}, 1.2 \mathrm{NaH}_{2} \mathrm{PO}_{4}, 1.3 \mathrm{MgCl}_{2}$, $2 \mathrm{CaCl}_{2}, 25 \mathrm{NaHCO}_{3}, 11$ glucose.

\section{CALCIUM IMAGING}

Slices were incubated in the dark with $25 \mu \mathrm{L}$ of a fura-2 AM solution $(1 \mathrm{mM}$ in DMSO $+0.8 \%$ pluronic acid; Molecular Probes). We performed imaging studies with a multibeam twophoton laser scanning system (Trimscope-LaVision Biotec) coupled to an Olympus microscope. Slices were imaged using a high numerical aperture objective (20×, NA 0.95, Olympus). Images $(4 \times 4$ binning) were acquired via a CCD camera (La Vision Imager 3QE) with a time resolution of $115-147 \mathrm{~ms}$ per frame. Size of the scan field $(444 \times 336 \mu \mathrm{m})$ and duration of the movies (1000 frames) were unchanged. We first took images of the GFP-expressing neurons located in the mesencephalon (laser at $910 \mathrm{~nm}$ ) before acquiring spontaneous fura-2 fluorescence changes (laser at $780 \mathrm{~nm}$ ). To verify the location of the recorded field, at the end of the imaging session we bleached the fura-2 fluorescence from the field and observed its corresponding location on the GFP image. During the analysis, GFP-expressing fura 2-loaded neurons were identified by superposing the two fields. We performed analysis of the calcium activity with custommade software written in Matlab (MathWorks) (Bonifazi et al., 2009). Active cells were neurons exhibiting any $\mathrm{Ca}^{2+}$ event of at least $5 \% \mathrm{DF} / \mathrm{F}$ deflection within the period of recording. $\mathrm{Ca}^{2+}$ spike or $\mathrm{Ca}^{2+}$ plateau cells were neurons exhibiting at least one $\mathrm{Ca}^{2+}$ spike or one $\mathrm{Ca}^{2+}$ plateau within the period of recording. A calcium plateau sustained a calcium level for at least 30 frames as opposed to a calcium spike which started decaying at the peak. We computed the activity correlation of cell pairs as previously described (Crepel et al., 2007; Dehorter et al., 2011).

\section{PATCH CLAMP RECORDINGS}

We performed all recordings at $32^{\circ} \mathrm{C}$. Cells were visualized with infrared-differential interference optics (Axioskop2; Zeiss). For whole-cell current clamp recordings the pipette $(6-10 \mathrm{M} \Omega$ ) contained the following (in $\mathrm{mM}$ ): $128.5 \mathrm{~K}$-gluconate, $11.5 \mathrm{KCl}$, $1 \mathrm{CaCl}_{2}, 10 \mathrm{HEPES}, 10$ EGTA, $2.5 \mathrm{MgATP}$ and $0.3 \mathrm{NaGFP}, \mathrm{pH}$ 7.2-7.4 (275-285 mOsm). We determined input membrane resistance $\left(R_{m}\right)$ by on-line fitting analysis of the transient currents in response to a $5-10 \mathrm{mV}$ pulse at $V_{H}=-60 \mathrm{mV}$. Criteria for considering a recording included $R_{m}>100 \mathrm{M} \Omega$. The input resistance $\left(R_{m}\right)$ of mDA neurons decreased significantly from $355 \pm 39 \mathrm{M} \Omega$ before birth (E18, $n=8)$ to $203 \pm 31 \mathrm{M} \Omega$ at P5-P7 $(n=5, p<$ 0.05 , Mann-Whitney test). In parallel, the percentage of $\mathrm{mDA}$ neurons displaying the hyperpolarization-activated cationic current Ih increased from $61 \%$ at E18 to $100 \%$ at P7. Amplitude of action potentials was measured from peak to after spike hyperpolarization (AHP) potential and their duration half-way between threshold and peak (half-width duration).

\section{AMPEROMETRY}

Coronal slices were placed in a chamber and perfused with $\mathrm{O}_{2}$ saturated ACSF at $32^{\circ} \mathrm{C}$. We measured the evoked and not the spontaneous release of dopamine as performed in P9-14 primary cultures of mDA neurons (Kim et al., 2008) or 30-40 days organotypic slices of the striatum (Cragg et al., 1998) because the high perfusion rate of ACSF needed to keep slices healthy prevents such a measure. Stimulation was performed with a bipolar tungsten electrode with a tip separation of $100 \mu \mathrm{m}$ (World Precision Instruments TST33C05KT, stereo tungsten electrode, in vitro impedance of $1 \mathrm{M} \Omega$ ) inserted into the striatum. We did not study DA overflow in response to median forebrain bundle (MFB) stimulation because medial sagittal slices containing the MFB cannot be reliably obtained at embryonic stages. To evoke a reproducible DA release, we used a train of four $100 \mathrm{~Hz}$ square pulses of $50 \mathrm{~V}$ amplitude and $100 \mu$ s duration. To monitor the electrically evoked dopamine release, we used continuous amperometry with carbon fiber electrodes because it gives similar results as cyclic voltammetry in the striatum (Schmitz et al., 2001). The carbon fiber electrode (active surface $10 \mu \mathrm{m}$ in diameter and $500 \mu \mathrm{m}$ long; World Precision Instruments, CF10) was implanted into the striatum at an angle of $60^{\circ}$ from vertical so that the entire length of the active surface was inside the slice at a depth of about $50 \mu \mathrm{m}$ from the surface. This was done in the ventrolateral and dorsomedial striatum where the evoked DA release was maximal and minimal respectively. The carbon fiber electrode was connected to a potentiostat (MicroC, World Precision instruments) to apply voltage and measure current. To measure DA release, the imposed voltage between the carbon fiber electrode and the $\mathrm{Ag} / \mathrm{AgCl}$ pellet was $0.5 \mathrm{~V}$. In response to the stimulus train, the current generated by oxidation of evoked 
dopamine released was recorded. To separate the evoked current from an artefact, the same stimulus protocol was done with $0 \mathrm{~V}$ applied between the carbon electrode and the $\mathrm{Ag} / \mathrm{AgCl}$ reference. At this voltage, no oxidation of DA should occur. Signals were digitized using a Digidata data acquisition system (Digidata 1440A) coupled to a PC running the clampex nine program responding to the Multiclamp700A amplifier. Results are presented as maximum response obtained per brain hemisphere. To measure DA release during the blockade of dopamine reuptake, we incubated the slices in nomifensine $(10 \mu \mathrm{M})$ for a minimum of $20 \mathrm{~min}$. To test the calcium-dependence of dopamine release, we used a modified ACSF containing the following (in $\mathrm{mM}): 126 \mathrm{NaCl}, 3.5 \mathrm{KCl}, 1.2 \mathrm{NaH}_{2} \mathrm{PO}_{4}, 3.3 \mathrm{MgCl}_{2}, 25 \mathrm{NaHCO}_{3}$, 11 glucose.

\section{IMMUNOCYTOCHEMISTRY}

To visualize the $\mathrm{TH}$-positive fibers in the striatum we performed immunocytochemistry of $\mathrm{TH}$ in embryonic and early postnatal slices, and to identify the recorded cells we revealed the neurobiotin injected during whole-cell recordings in recorded slices, as previously described (Dehorter et al., 2009). Dendritic and axonal fields were reconstructed for morphological analysis using the Neurolucida system (MicroBrightField Inc., Colchester, VT).

\section{DRUGS}

Drugs were prepared as concentrated stock solutions and diluted in ACSF for bath application. Gabazine, D-amino pyruvate (D-APV), 6-cyano-7-nitroquinoxaline 2,3-dione (CNQX), Tetrodotoxin (TTX), Nifedipine, Thapsigargin and Nomifensine maleate were purchased from Sigma (St. Louis, MO, USA). $\omega$-conotoxin GVIA was purchased from Alomone Labs (Jerusalem, Israel).

\section{STATISTICAL ANALYSIS}

Statistical results are given as means \pm SEM. We performed statistical analysis using GraphPad Prism (GraphPad Software, Inc., La Jolla, CA): one-way ANOVA (Tukey's Test as post hoc test), Mann-Whitney test (non-parametric $t$-test), and paired $t$-tests as indicated in the results section. Differences were considered significant at $p \leq 0.05$ ( $^{* * *}$ for $p \leq 0.001$, ${ }^{* *}$ for $p \leq 0.01$ and ${ }^{*}$ for $p \leq 0.05)$. We grouped the P5 and P7 sets of data since they did not present a statistical difference. In the box plots of Figures 1A and $5 \mathrm{~B}$ the bottom and top of the boxes represent the $25^{\text {th }}$ and $75^{\text {th }}$, the band inside the box is the $50^{\text {th }}$ percentile (median) and the top and bottom vertical bars (whiskers) denote the maximum and minimum values.

\section{RESULTS}

EMBRYONIC mDA NEURONS PROJECT TO THE DEVELOPING STRIATUM Axons of E16 neurobiotin-filled mDA neurons project rostrally toward the striatum even when their somas do not have dendrites yet (Figure 1A). The dendritic length and number of dendritic ends of mDA neurons significantly increase from E16 (90 \pm $31 \mu \mathrm{m} ; 1.5 \pm 0.4$ ends; $n=13)$ to $\mathrm{E} 18(245 \pm 66 \mu \mathrm{m} ; 3.9 \pm 0.6$ ends; $n=7 ; p<0.05$, Mann-Whitney test), and from E18 to P0 (1031 $\pm 287 \mu \mathrm{m}, 12 \pm 3$ ends; $n=6$; $p<0.05$, Mann-Whitney test) (Figure 1A). Accordingly, a substantial diffuse innervation

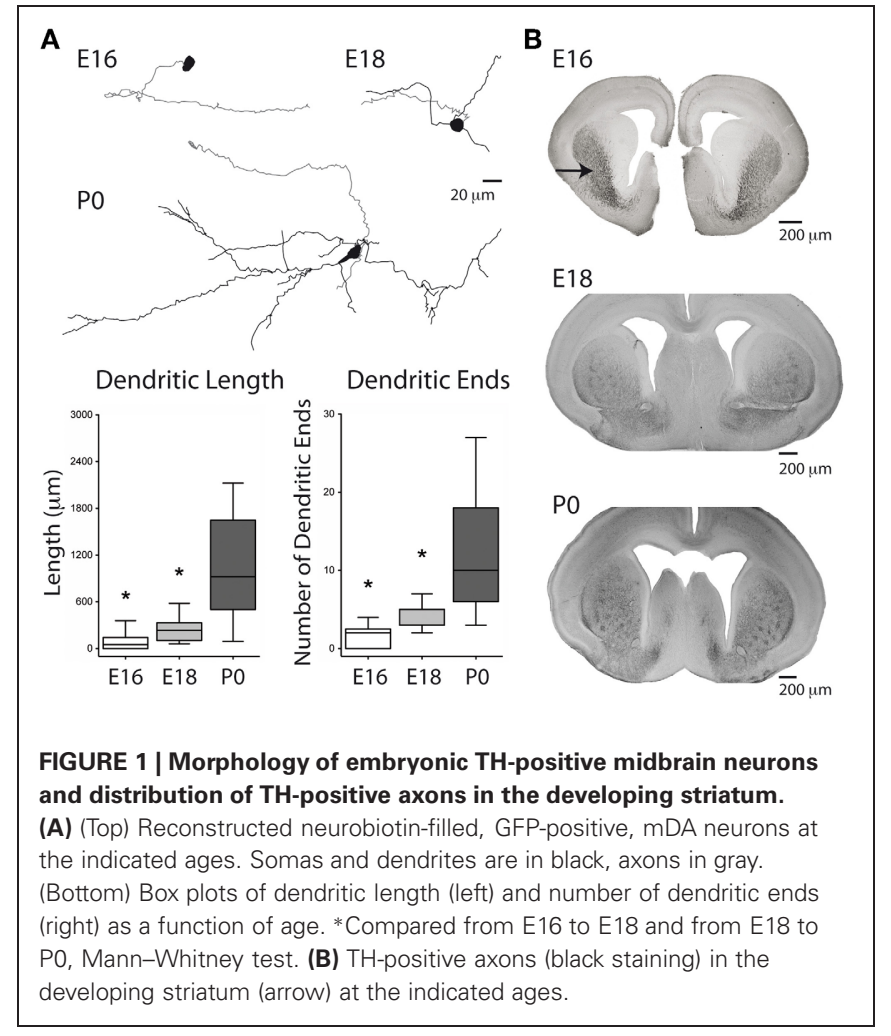

of the striatum by $\mathrm{TH}^{+}$fibers is already present at E14-E16 in the ventro-lateral part of the striatum (Ohtani et al., 2003) (Figure 1B). Later at E18-P0, $\mathrm{TH}^{+}$fibers invade the more dorsal regions of the striatum. Therefore, mDA neurons extend long axons that reach the striatum already at E16 before developing their dendritic tree.

\section{EMBRYONIC mDA NEURONS SPONTANEOUSLY GENERATE INTRINSICALLY DRIVEN $\mathrm{Ca}^{2+}$ EVENTS}

From the 1052 fura-2-loaded/GFP-positive (mDA) imaged neurons recorded in a total of 45 movies, 412 spontaneously generated calcium events (Figures 2A,B). mDA neurons were already active at E16, the youngest age tested (Figures 2C,D). Embryonic (E16-E18) and early postnatal (P0-P7) mDA neurons generated two patterns of activity (Crepel et al., 2007): $\mathrm{Ca}^{2+}$ spikes that were sporadic brief $\mathrm{Ca}^{2+}$ events $(1.41 \pm 0.08 \mathrm{~s}$ duration, $n=264$ neurons in 45 fields referred as 264/45) and long lasting $\mathrm{Ca}^{2+}$ plateaus ( $9 \pm 0.3 \mathrm{~s}$ duration, 106/45; Figure 2C). These two patterns of activity significantly differed in duration $(p<$ 0.05 , Mann-Whitney test). The percent of mDA neurons generating $\mathrm{Ca}^{2+}$ spikes was stable between E16 (28 $\pm 4 \%$ of fura-2 AM-loaded GFP neurons, 131/11), and P0 (32 $\pm 4 \%, 87 / 13)$, significantly decreased at P3 $(11 \pm 5 \%, 30 / 4, p<0.001$, MannWhitney test, data not shown) and then remained stable until P7 $\left(13 \pm 3 \%, 11 / 12\right.$; Figure 2D). $\mathrm{Ca}^{2+}$ spikes had a low frequency at E16-E18 $(0.05 \pm 0.01 \mathrm{~Hz}, 166 / 16)$ that increased at P0 $(0.09 \pm$ $0.01 \mathrm{~Hz})$ and $\mathrm{P} 7(0.16 \pm 0.04 \mathrm{~Hz}$, data not shown $)$. The percent of mDA neurons generating $\mathrm{Ca}^{2+}$ plateaus was low at E16 $(11 \pm 3 \%$, $37 / 11)$ and remained stable until P0 (10 $\pm 2 \%, 43 / 13)$ before decreasing at P7 $\left(4 \pm 2 \%, 5 / 12\right.$; Figure 2D). $\mathrm{Ca}^{2+}$ plateaus had 


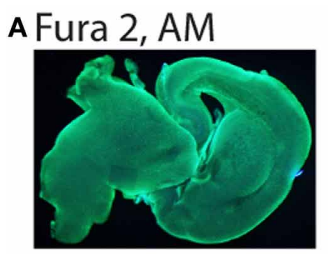

B Fura 2, AM cells

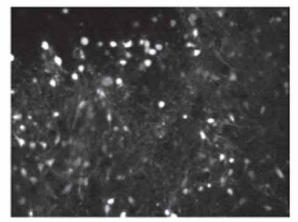

Contours Fura 2 cells

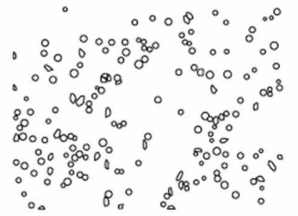

Overlap contours

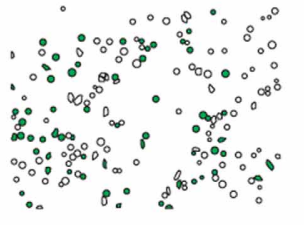

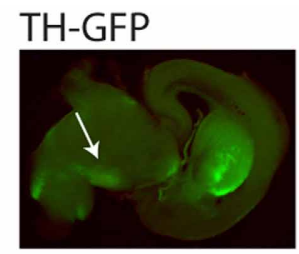

TH-GFP cells

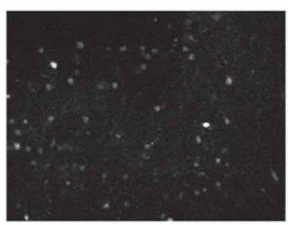

Contours TH-GFP cells

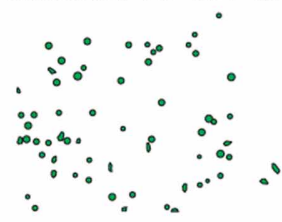

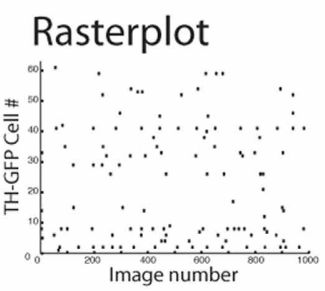

\section{c Calcium Spikes}

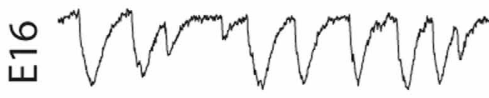

๑

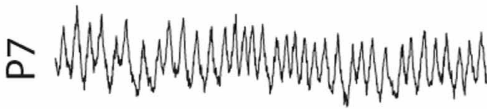
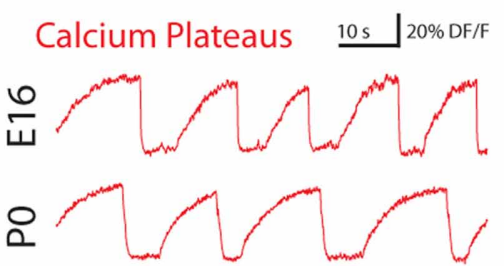

D

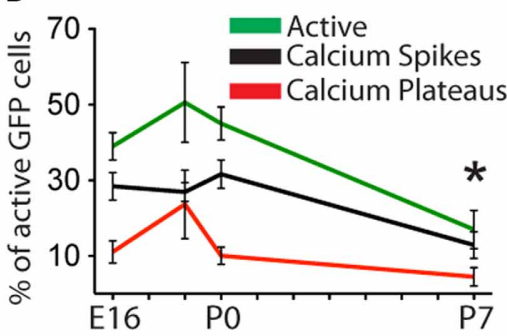

FIGURE 2 | Spontaneous $\mathrm{Ca}^{2+}$ activities of embryonic and early postnatal mDA neurons. (A) Photomicrograph of the same fura 2-loaded sagittal slice from a PO TH-GFP mouse excited with UV (left) or blue light (right) to show the slice loaded with the calcium dye fura 2-AM and the location of the GFP-positive structures, respectively. Recordings were performed in the midbrain, in the region of the substantia nigra (SN, white arrow). (B) Fluorescence images of the cells in the same fura 2-loaded (top left) and GFP-positive (top right) SN region. Manually detected contours of the cells from the corresponding fluorescence images (Middle). Superimposition of the two fields (Bottom, left). Open contours indicate fura 2-loaded cells and green-filled contours are fura 2-loaded/GFP-positive neurons. Rasterplot of the $\mathrm{Ca}^{2+}$ activity of the active fura 2-loaded/GFP-positive neurons from the field shown in (B) (Bottom, right). (C) Representative calcium fluorescence traces from GFP-positive neurons at the indicated ages showing spontaneously generated $\mathrm{Ca}^{2+}$ spikes (black) or $\mathrm{Ca}^{2+}$ plateaus (red). (D) Mean percentage ( \pm SEM) of all active neurons (green), fura 2-loaded/GFP-positive midbrain neurons evoking at least one $\mathrm{Ca}^{2+}$ spike (black) or one $\mathrm{Ca}^{2+}$ plateau (red), as a function of age. *Compared to E16, E18, and P0, One-Way ANOVA. a similar mean frequency $(0.040 \pm 0.004 \mathrm{~Hz}$ vs. $0.08 \pm 0.04 \mathrm{~Hz}$; $p=0.28$ Mann-Whitney test) and a similar mean duration $(8.9 \pm 1.7 \mathrm{~s}$ vs. $8.6 \pm 3.7 \mathrm{~s} ; p=0.67 \mathrm{Mann}-$ Whitney test $)$ at E16 and P7 (data not shown). Overall, the percent of spontaneously active $\mathrm{mDA}$ neurons generating at least one $\mathrm{Ca}^{2+}$ spike and/or one $\mathrm{Ca}^{2+}$ plateau did not change significantly between E16, E18, and P0 $(39.5 \pm 3.6 \%, 50.6 \pm 10.5 \%$, and $45 \pm 4 \%$ of imaged mDA neurons, respectively, $p=0.4$ between E16 and E18, and $p=0.7$ between E18 and P0), and then significantly declined from P0 to P7 ( $17 \pm 5 \%$ at P7; $p<0.01$, Mann-Whitney test). $\mathrm{Ca}^{2+}$ spikes and $\mathrm{Ca}^{2+}$ plateaus were poorly correlated between neurons $(0.2 \%$ cell pairs significantly correlated, see materials and methods) at all ages tested.

$\mathrm{Ca}^{2+}$ spikes and $\mathrm{Ca}^{2+}$ plateaus were sensitive to blockers of $\mathrm{Na}^{+} / \mathrm{Ca}^{2+}$ voltage-gated channels since TTX $(1 \mu \mathrm{M})+$ nifedipin $(10 \mu \mathrm{M})$ dramatically decreased the percent of active mDA neurons from $30.2 \pm 7.7 \%$ to $4.3 \pm 1.3 \%$ at $\mathrm{E} 16 \quad(p<0.05$, paired $t$-test, $n=4$ slices), i.e., it decreased the activity of
$94 \pm 4 \%$ of the previously active E16 mDA cells (Figure 3A). Nifedipin alone at a concentration that specifically blocks L-type $\mathrm{Ca}^{2+}$ channels $(3 \mu \mathrm{M})$ decreased the calcium activity of $44 \pm 14 \%$ of the previously active P1 mDA neurons $(n=8$ slices, Figure 3B). Furthermore, $\omega$-conotoxin GVIA $(1 \mu \mathrm{M})$, a specific blocker of $\mathrm{N}$-type $\mathrm{Ca}^{2+}$ channels, decreased the calcium activity of $57 \pm 7 \%$ of the previously active $\mathrm{P} 1 \mathrm{mDA}$ neurons $(n=$ 4 slices, Figure 3C). In contrast, $\mathrm{Ca}^{2+}$ events recorded at $\mathrm{P0}$ were totally insensitive to ionotropic GABA and glutamate receptor antagonists $(44.9 \pm 2.3 \%$ active vs. $37.2 \pm 3.7 \%$ at $\mathrm{P} 0, p=$ 0.7 , paired $t$-test, i.e., $76.5 \pm 6 \%$ of the previously active cells remained unaffected, Figure 3D). A few days later, at P3 the same synaptic blockers decreased the calcium activity of $69 \pm 8 \%$ of the previously active mDA neurons ( $n=4$ slices, Figure $3 \mathrm{E}$ ). In contrast, depletion of intracellular $\mathrm{Ca}^{2+}$ stores with thapsigargin $(10 \mu \mathrm{M})$ did not affect the number of cells generating $\mathrm{Ca}^{2+}$ spikes and $\mathrm{Ca}^{2+}$ plateaus, nor the frequency of these events $(24.5 \pm 4.1 \%$ control active vs. $24.6 \pm 4.3 \%$ at $\mathrm{P} 1, p=0.9$, paired 

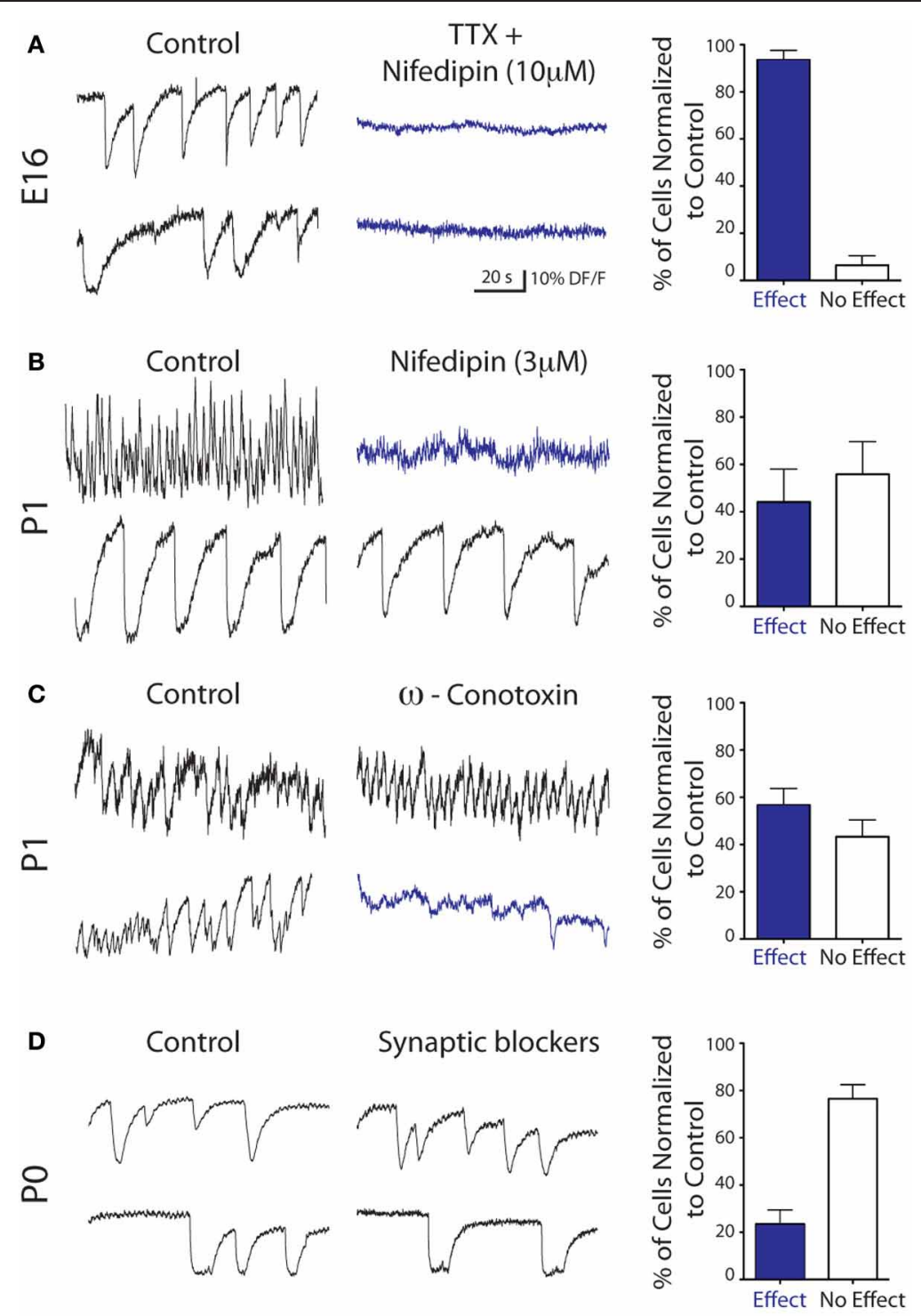

E

Control

Synaptic blockers
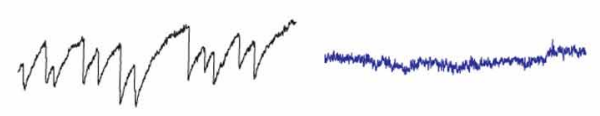

$\stackrel{m}{\alpha}$
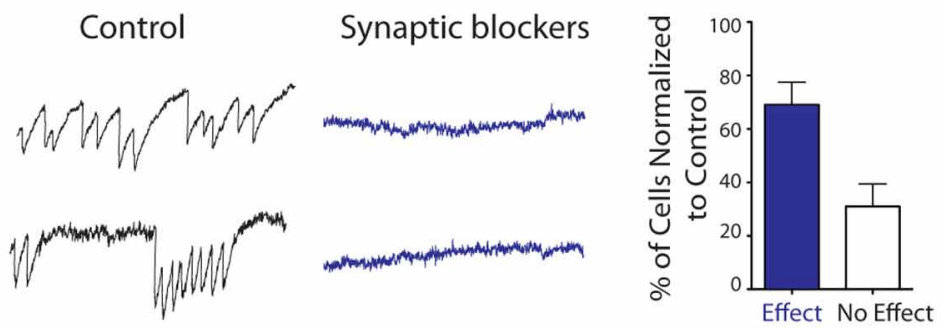

FIGURE 3 | Pharmacology of the spontaneous $\mathrm{Ca}^{2+}$ activities of embryonic and early postnatal mDA neurons. Representative calcium fluorescence traces from mDA neurons and corresponding quantitative data at the indicated ages showing the effect of TTX
$(1 \mu \mathrm{M})$-nifedipin $(10 \mu \mathrm{M})$ (A) nifedipin $(3 \mu \mathrm{M})$ (B) $\omega$-conotoxin GVIA (1 $\mu \mathrm{M})$ (C) and blockers of ionotropic glutamate and GABA receptors [APV $(40 \mu \mathrm{M})$ - CNOX (10 $\mu \mathrm{M})$-Gabazine $(5 \mu \mathrm{M}), \mathbf{D}$ and $\mathbf{E}]$. $t$-test, i.e., $76 \pm 10 \%$ of the active GFP-positive cells identified before thapsigargin treatment had their activity unaffected by the treatment, data not shown). These results showed that E16-P1 $\mathrm{mDA}$ neurons spontaneously generate intrinsically driven,
$\mathrm{L}$ - and $\mathrm{N}$-type mediated $\mathrm{Ca}^{2+}$ events. Only starting from $\mathrm{P} 3$, are these $\mathrm{Ca}^{2+}$ events sensitive to synaptic blockers suggesting that synapse-driven inputs to $\mathrm{mDA}$ neurons operate during the first postnatal week but not before. 

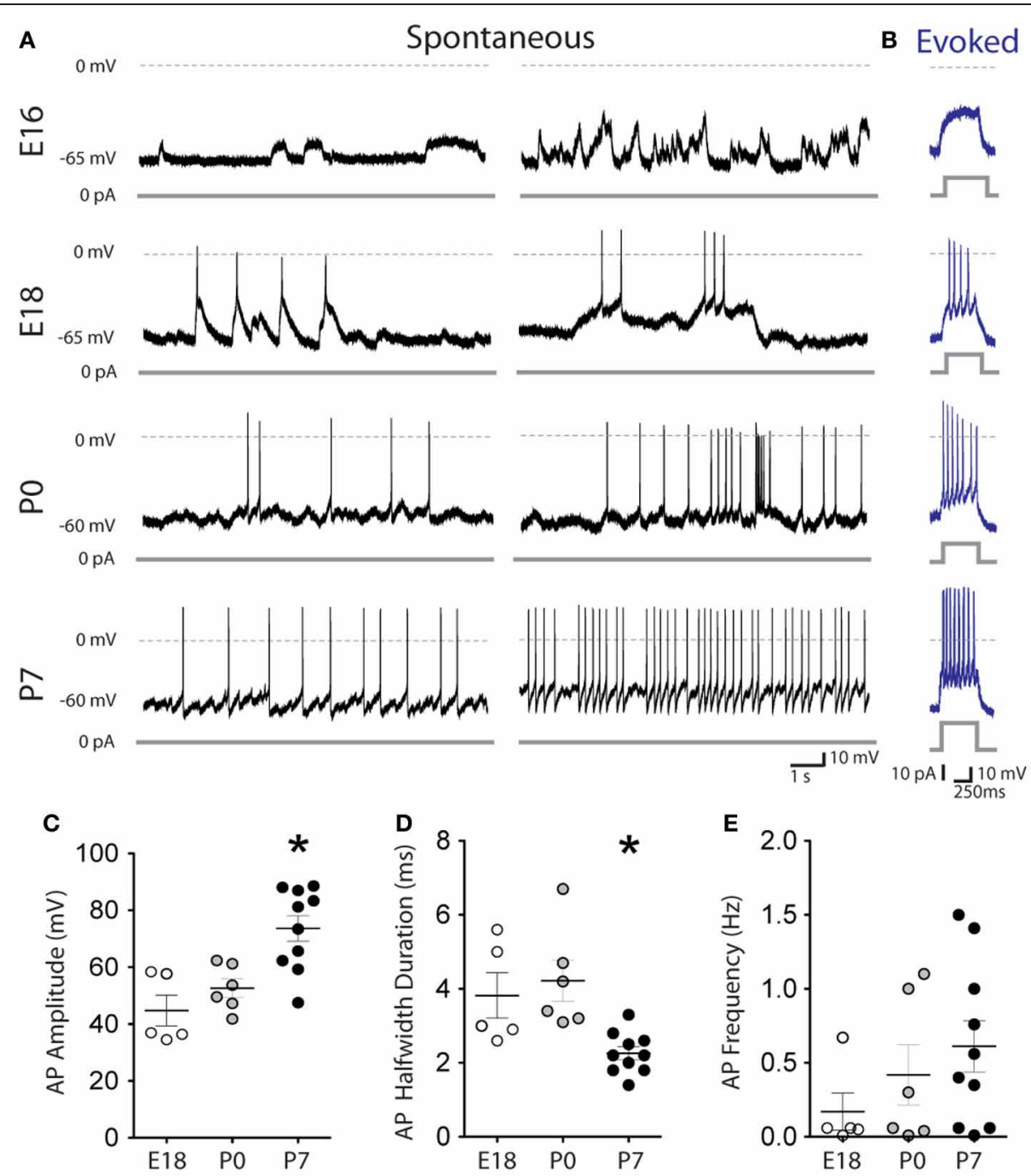

FIGURE 4 | Firing patterns of embryonic and early postnatal mDA neurons. Spontaneous (A) and evoked (B) membrane potential changes recorded in whole-cell configuration, current clamp mode from midbrain
GFP-positive neurons at the indicated ages. Distribution of the amplitude (C) half-width duration (D) and frequency (E) of spontaneous $\mathrm{Na}^{+}$action potentials as a function of age. *Compared to E18 and P0.

\section{AT BIRTH, HALF THE mDA NEURONS SPONTANEOUSLY GENERATE INTRINSICALLY DRIVEN $\mathrm{Na}^{+}$ACTION POTENTIALS}

In contrast to their capacity to generate $\mathrm{Ca}^{2+}$ events (Figures $2 \mathrm{~B}$ and 3), E16 embryonic mDA neurons $(n=16)$ did not generate spontaneous (Figure 4A) or evoked (Figure 4B) $\mathrm{Na}^{+}$spikes. They started to generate spontaneous $\mathrm{Na}^{+}$spikes around birth since $28 \%$ and $50 \%$ of the recorded $\mathrm{mDA}$ neurons at E18 and P0, respectively, $(n=18 ; n=12)$, spontaneously fired action potentials with a mean amplitude of $44.8 \pm 5.4 \mathrm{mV}$ and $52.6 \pm 3.3 \mathrm{mV}$ (Figures 4A-C). At P7, 100\% of the recorded mDA neurons were spontaneously active (amplitude: $73.6 \pm 4.5 \mathrm{mV} ; n=10$ ). Spike half-width duration significantly decreased from E18-P0 $(3.8 \pm 0.6 \mathrm{~ms}, n=5 ; 4.2 \pm 0.6, n=6)$ to P7 ( $2.2 \pm 0.2 \mathrm{~ms}, n=$ $10 ; p<0.05$, Mann-Whitney test; Figure 4D) but mean spontaneous firing frequency did not significantly increase from E18-P0 to $\mathrm{P} 7(0.2 \pm 0.1 \mathrm{~Hz}$ at $\mathrm{E} 18 ; 0.4 \pm 0.2 \mathrm{~Hz}$ at $\mathrm{P} 0 ; 0.6 \pm 0.2 \mathrm{~Hz}$ at P7; Figure 4E). Therefore, half of the mDA neurons are already capable of generating spikes at birth (see Figure 2).

\section{WHEN STIMULATED, TYROSINE-HYDROXYLASE POSITIVE FIBERS RELEASE DOPAMINE IN THE STRIATUM AT BIRTH}

In agreement with the presence of $\mathrm{TH}^{+}$fibers in the embryonic striatum, we detected from E18 DA release in the striatum in response to local stimulation $(19.7 \pm 1.5 \mathrm{pA}, n=13$; Figures 5A,B). This evoked DA release significantly increased at birth (P0) to $43.1 \pm 4.3 \mathrm{pA}(p<0.001$, One-way ANOVA; $n=25)$ and stayed stable during the first postnatal week. The evoked DA release observed at E18 and P0 was entirely dependent on external $\mathrm{Ca}^{2+}$ ions, since the response disappeared in the absence of $\mathrm{Ca}^{2+}$ ions, and was rescued in the presence of $\mathrm{Ca}^{2+}$ ions (Figures 5A,B) To further support the view that the changes in oxidation current evoked by striatal stimulation actually correspond 


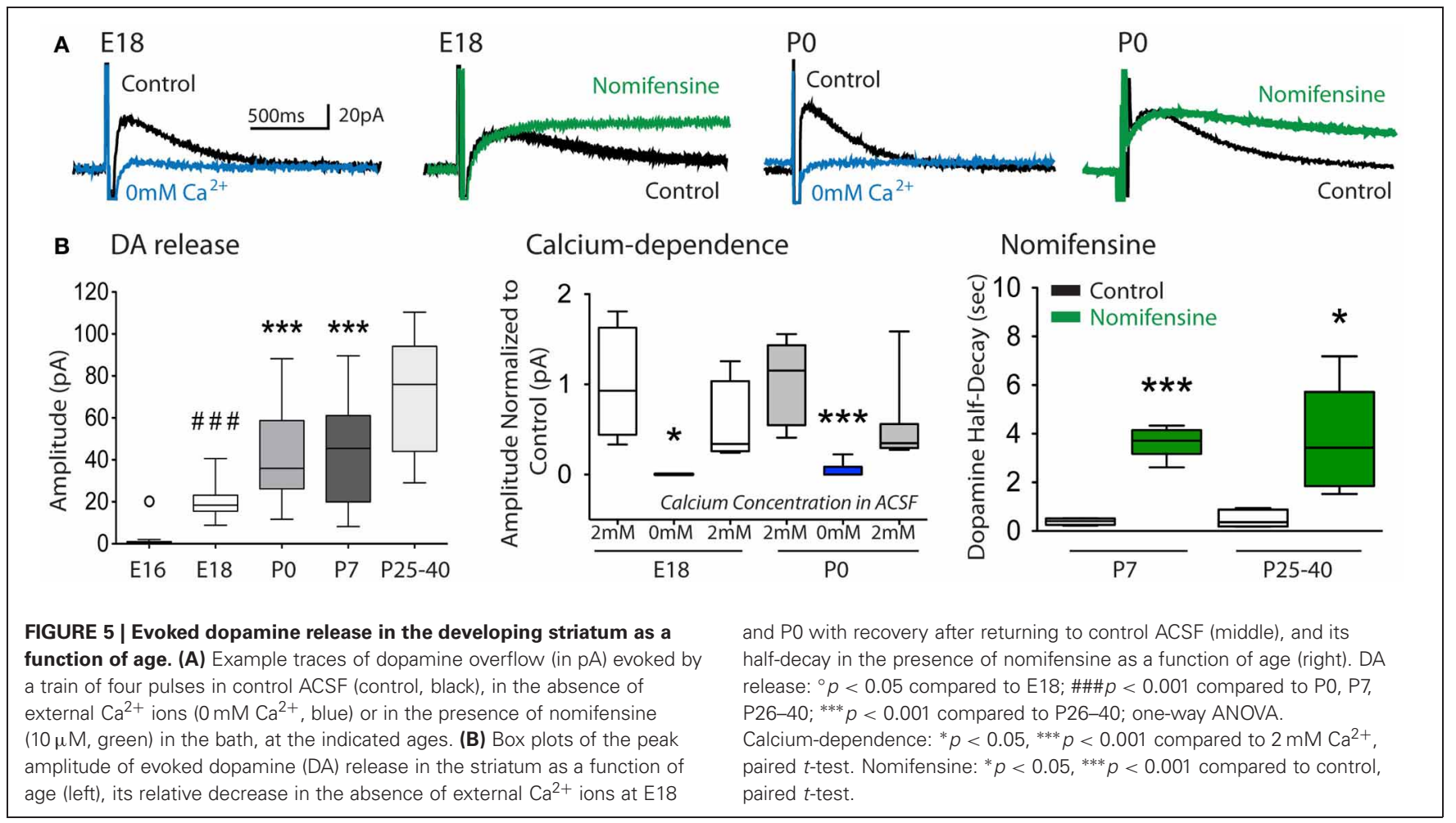

to an evoked dopamine overflow (Benoit-Marand et al., 2000), nomifensine $(10 \mu \mathrm{M})$ was added to the perfusion medium to inhibit dopamine reuptake. This did not alter the rising phase of dopamine overflow which corresponds to dopamine release, but slowed the kinetics of the decreasing phase which depends on dopamine reuptake (Figure 5A). Dopamine half-decay was significantly increased by nomifensine treatment $(20 \mathrm{~min})$ at P7 $(0.4 \pm 0.1$ to $3.7 \pm 0.3 \mathrm{~s}, p<0.001$ paired $t$-test, $n=5)$, and P25-40 $(0.5 \pm 0.2$ to $3.7 \pm 1 \mathrm{~s}, p<0.05$ paired $t$-test, $n=5$; Figure 5B). These results confirmed the perinatal expression of the dopamine transporter in rodents (Galineau et al., 2004). At E18 and P0, the decay phase in the presence of nomifensine was too long and precluded its measure. This could be due to the fact that at these young ages the competitive inhibitor nomifensine, at the dose used, could not be rapidly displaced from its binding sites on the dopamine transporter (Tuomisto, 1977; Jones et al., 1995; Katz et al., 2000) by the small amount of evoked dopamine overflow.

\section{DISCUSSION}

Here we show that mouse $\mathrm{mDA}$ neurons project to the striatum and spontaneously generate intrinsically driven $\mathrm{Ca}^{2+}$ events mediated by $\mathrm{N}$ - and L-type $\mathrm{Ca}^{2+}$ channels during embryonic life. At birth, they generate $\mathrm{Na}^{+}$spikes and release dopamine in the developing striatum in a $\mathrm{Ca}^{2+}$-dependent manner.

The dynamic two-photon calcium imaging technique enabled us to record the activity of large neuronal populations when compared to patch-clamp recordings of single neurons. Around $50 \%$ of mDA neurons generated spontaneous voltage-gated $\mathrm{Ca}^{2+}$ spikes and/or $\mathrm{Ca}^{2+}$ plateaus already at E16. Both types of activity previously described in the developing cortex, hippocampus and striatum, correspond to single action potentials and bursts of spikes, respectively, (Crepel et al., 2007; Allene et al., 2008; Dehorter et al., 2011). The general sequence of patterns generated by $\mathrm{mDA}$ neurons is not without similarities with that reported in cortical and basal ganglia structures in these earlier studies. Clearly, non-synapse-driven, voltage-gated currents precede the operation of synapse-driven events. However, in contrast to cortical and striatal networks, $\mathrm{Ca}^{2+}$ plateaus were not correlated between mDA neurons. Since correlated calcium plateaus in small cell assemblies depend on gap junctions required for the formation of synaptically connected networks (Todd et al., 2010), their absence might be accounted for by the absence of connections (recurrent collaterals) between adult $\mathrm{A} 9 \mathrm{mDA}$ neurons (Chen et al., 2011). This can also be due to the small number of $\mathrm{mDA}$ neurons generating $\mathrm{Ca}^{2+}$ plateaus in each imaged field, thus reducing the probability of correlation. Also, whether the synapse-driven patterns recorded from mDA neurons are similar to the giant depolarizing potentials (GDPs) described in cortical and more recently in striatal structures (Dehorter et al., 2011) remains to be clarified. The difficulty of finding mDA neurons generating synchronized synapse-driven events most likely reflects the maturation of incoming fibers to the structure investigated. In contrast to the hippocampus and neocortex, but similarly as the striatum, there are no intrinsic glutamatergic neurons in the $\mathrm{SN}$, thereby conditioning the generation of synchronized patterns by the arrival of external inputs: here the pedunculopontine and subthalamic nuclei that may have a delayed maturation. The other source of glutamate could arise from the recurrent collaterals of the midbrain dopaminergic neurons that co-release glutamate in the adult striatum (Tecuapetla et al., 2010). At any rate, the development of an in vitro embryonic slice with enough intact inputs from these structures is needed to solve this issue. 
Although we cannot completely exclude the possibility that a subthreshold calcium-dependent dopamine release is present before E18-P0 this would be without functional consequence since $\mathrm{Na}^{+}$spikes required to that effect are not generated by most mDA neurons before E18. Interestingly, around birth, mDA neurons generate $\mathrm{Ca}^{2+}$ events partly mediated by $\mathrm{N}$-type $\mathrm{Ca}^{2+}$ channels, the same channels involved in synaptic DA release in the adult rodent striatum in vivo and in vitro (Herdon and Nahorski, 1989; Bergquist et al., 1998).

What could be the functional role of dopamine signals in the developing striatum? Dopamine has been suggested to modulate multiplication, migration, and wiring of target neurons. The activation of dopamine receptors by exogenous dopamine or dopamine agonists regulates the cell cycle of striatal progenitors in the lateral ganglionic eminence in explant cultures or in mice in vivo from E13 (Ohtani et al., 2003). From E15, dopaminergic agonists, or the invalidation of D1 or D2 receptors, differentially modulate the migration of GABAergic interneurons to the cerebral wall in embryonic mouse forebrain organotypic slices (Crandall et al., 2007). In addition, the activation of dopamine receptors in primary striatal neuronal cultures (7-14 days cultures obtained from E16-17 striata) limits the extent of collateral GABAergic synaptogenesis between developing medium spiny neurons (Goffin et al., 2010). Early effects of dopamine before E18 could result from activity-independent release of dopamine in the ganglionic eminences as described for glutamate and GABA in the developing hippocampus and shown to be quite efficient

\section{REFERENCES}

Allene, C., Cattani, A., Ackman, J. B., Bonifazi, P., Aniksztejn, L., Ben-Ari, Y., and Cossart, R. (2008). Sequential generation of two distinct synapse-driven network patterns in developing neocortex. J. Neurosci. 28, 12851-12863.

Benoit-Marand, M., Jaber, M., and Gonon, F. (2000). Release and elimination of dopamine in vivo in mice lacking the dopamine transporter: functional consequences. Eur. J. Neurosci. 12, 2985-2992.

Bergquist, F., Jonason, J., Pileblad, E., and Nissbrandt, H. (1998). Effects of local administration of L-, N-, and P/Q-type calcium channel blockers on spontaneous dopamine release in the striatum and the substantia nigra: a microdialysis study in rat. J. Neurochem. 70, 1532-1540.

Bonifazi, P., Goldin, M., Picardo, M. A., Jorquera, I., Cattani, A., Bianconi, G., Represa, A., Ben-Ari, Y., and Cossart, R. (2009). GABAergic hub neurons orchestrate synchrony in developing hippocampal networks. Science 326, 1419-1424.

Chen, B. T., Patel, J. C., Moran, K. A., and Rice, M. E. (2011). Differential calcium dependence of axonal versus somatodendritic dopamine release, with characteristics of

in modulating migration (Demarque et al., 2002; Manent and Represa, 2007). The possible implications of activity-dependent release of DA on striatal maturation remain to be investigated. But, interestingly, the fraction of medium spiny neurons generating glutamate and GABA spontaneous synaptic activity in the developing striatum also considerably develops during the first postnatal week in mice (Dehorter et al., 2011), suggesting an important stimulation of the developmental process after birth.

To conclude, the present work suggests a developmental sequence of $\mathrm{mDA}$ neurons with features that are common and specific to these neurons. In a previous study, we showed that striatal neurons follow an abrupt alteration of their properties in time to start controlling motricity in pups (Dehorter et al., 2011). Future studies will have to interconnect these events and determine the impact of dopaminergic synapses on the operation of early striatal neurons.

\section{ACKNOWLEDGMENTS}

We thank Dr. Baker (Cornell University) for the gift of TH-GFP mice, F. Gonon for his help with the amperometry technique and B. Bloem for his help in preliminary experiments. Diana C. Ferrari was funded by Fondation pour la Recherche Médicale (FRM) and Association France Parkinson. This work was supported by grants from Institut National de la Santé et de la Recherche Médicale (Inserm), and Fédération de Recherche sur le Cerveau $(\mathrm{CH})$.

pup locomotion coincides with loss of NR2C/D-Mediated corticostriatal EPSCs and dampening of striatal network immature activity. Front. Cell. Neurosci. 5:24. doi: 10.3389/fncel.2011.00024

Demarque, M., Represa, A., Becq, H., Khalilov, I., Ben Ari, Y., and Aniksztejn, L. (2002). Paracrine intercellular communication by a $\mathrm{Ca}^{2+}{ }_{-}$and SNARE-independent release of GABA and glutamate prior to synapse formation. Neuron 36, 1051-1061.

Fishell, G., and van der Kooy, D. (1989). Pattern formation in the striatum: developmental changes in the distribution of striatonigral projections. Brain Res. Dev. Brain Res. 45, 239-255.

Galineau, L., Kodas, E., Guilloteau, D., Vilar, M. P., and Chalon, S. (2004). Ontogeny of the dopamine and serotonin transporters in the rat brain: an autoradiographic study. Neurosci. Lett. 363, 266-271.

Gates, M. A., Torres, E. M., White, A., Fricker-Gates, R. A., and Dunnett, S. B. (2006). Re-examining the ontogeny of substantia nigra dopamine neurons. Eur. J. Neurosci. 23, 1384-1390.

Goffin, D., Ali, A. B., Rampersaud, N., Harkavyi, A., Fuchs, C., Whitton, P.
S., Nairn, A. C., and Jovanovic, J. N. (2010). Dopamine-dependent tuning of striatal inhibitory synaptogenesis. J. Neurosci. 30, 2935-2950.

Hall, A. C., Mira, H., Wagner, J., and Arenas, E. (2003). Region-specific effects of glia on neuronal induction and differentiation with a focus on dopaminergic neurons. Glia 43, 47-51.

Herdon, H., and Nahorski, S. R. (1989). Investigations of the roles of dihydropyridine and omega-conotoxin-sensitive calcium channels in mediating depolarisation-evoked endogenous dopamine release from striatal slices. Naunyn Schmiedebergs Arch. Pharmacol. 340, 36-40.

Jones, S. R., Garris, P. A., Kilts, C. D., and Wightman, R. M. (1995). Comparison of dopamine uptake in the basolateral amygdaloid nucleus, caudate-putamen, and nucleus accumbens of the rat. J. Neurochem. 64, 2581-2589.

Katz, J. L., Izenwasser, S., and Terry, P. (2000). Relationships among dopamine transporter affinities and cocaine-likediscriminative-stimulus effects. Psychopharmacology (Berl) 148, 90-98.

Kawano, H., Ohyama, K., Kawamura, K., and Nagatsu, I. (1995). 
Migration of dopaminergic neurons in the embryonic mesencephalon of mice. Brain Res. Dev. Brain Res. 86, 101-113.

Kim, Y., Park, M. K., and Chung, S. (2008). Voltage-operated $\mathrm{Ca}^{2+}$ channels regulate dopamine release from somata of dopamine neurons in the substantia nigra pars compacta. Biochem. Biophys. Res. Commun. 373, 665-669.

Manent, J. B., and Represa, A. (2007). Neurotransmitters and brain maturation: early paracrine actions of GABA and glutamate modulate neuronal migration. Neuroscientist 13, 268-279.

Matsushita, N., Okada, H., Yasoshima, Y., Takahashi, K., Kiuchi, K., and Kobayashi, K. (2002). Dynamics of tyrosine hydroxylase promoter activity during midbrain dopaminergic neuron development. J. Neurochem. 82, 295-304.

Moon, E. S., and Herkenham, M. (1984). Comparative development of striatal opiate receptors and dopamine revealed by autoradiography and histofluorescence. Brain Res. 305, 27-42.

Ohtani, N., Goto, T., Waeber, C., and Bhide, P. G. (2003). Dopamine modulates cell cycle in the lateral ganglionic eminence. J. Neurosci. 23, 2840-2850.

Sawamoto, K., Nakao, N., Kobayashi, K., Matsushita, N., Takahashi,
H., Kakishita, K., Yamamoto, A., Yoshizaki, T., Terashima, T., Murakami, F., Itakura, T., and Okano, H. (2001). Visualization, direct isolation, and transplantation of midbrain dopaminergic neurons. Proc. Natl. Acad. Sci. U.S.A. 98, 6423-6428.

Schmitz, Y., Lee, C. J., Schmauss, C., Gonon, F., and Sulzer, D. (2001). Amphetamine distorts stimulationdependent dopamine overflow: effects on D-2 autoreceptors, transporters, and synaptic vesicle stores. J. Neurosci. 21, 5916-5924.

Specht, L. A., Pickel, V. M., Joh, T. H., and Reis, D. J. (1981a). Lightmicroscopic immunocytochemical localization of tyrosine hydroxylase in prenatal rat brain. I. Early ontogeny. J. Comp. Neurol. 199, 233-253.

Specht, L. A., Pickel, V. M., Joh, T. H., and Reis, D. J. (1981b). Lightmicroscopic immunocytochemical localization of tyrosine hydroxylase in prenatal rat brain. II. Late ontogeny. J. Comp. Neurol. 199, 255-276.

Tecuapetla, F., Patel, J. C., Xenias, H., English, D., Tadros, I., Shah, F., Berlin, J., Deisseroth, K., Rice, M. E., Tepper, J. M., and Koos, T. (2010). Glutamatergic signaling by mesolimbic dopamine neurons in the nucleus accumbens. J. Neurosci. 30, 7105-7110.
Tepper, J. M., Trent, F., and Nakamura, S. (1990). Postnatal development of the electrical activity of rat nigrostriatal dopaminergic neurons. Brain Res. Dev. Brain Res. 54, 21-33.

Todd, K. L., Kristan, W. B. Jr., and French, K. A. (2010). Gap junction expression is required for normal chemical synapse formation. J. Neurosci. 30, 15277-15285.

Trent, F., Nakamura, S., and Tepper, J. M. (1991). Amphetamine exerts anomalous effects on dopaminergic neurons in neonatal rats in vivo. Eur. J. Pharmacol. 204, 265-272.

Tuomisto, J. (1977). Nomifensine and its derivatives as possible tools for studying amine uptake. Eur. J. Pharmacol. 42, 101-106.

van den Heuvel, D. M., and Pasterkamp, R. J. (2008). Getting connected in the dopamine system. Prog. Neurobiol. 85, 75-93.

van der Kooy, D., and Fishell, G. (1987) Neuronal birthdate underlies the development of striatal compartments. Brain Res. 401, 155-161.

Voorn, P., Kalsbeek, A., JorritsmaByham, B., and Groenewegen, H. J. (1988). The pre- and postnatal development of the dopaminergic cell groups in the ventral mesencephalon and the dopaminergic innervation of the striatum of the rat. Neuroscience $25,857-887$.
Washio, H., Takigachi-Hayashi, K., and Konishi, S. (1999). Early postnatal development of substantia nigra neurons in rat midbrain slices: hyperpolarization-activated inward current and dopamine-activated current. Neurosci. Res. 34, 91-101.

Conflict of Interest Statement: The authors declare that the research was conducted in the absence of any commercial or financial relationships that could be construed as a potential conflict of interest.

Received: 16 December 2011; accepted: 11 February 2012; published online: 08 March 2012.

Citation: Ferrari DC, Mdzomba BJ, Dehorter N, Lopez C, Michel FJ, Libersat $F$ and Hammond $C$ (2012) Midbrain dopaminergic neurons generate calcium and sodium currents and release dopamine in the striatum of pups. Front. Cell. Neurosci. 6:7. doi: 10.3389/fncel. 2012.00007

Copyright (c) 2012 Ferrari, Mdzomba, Dehorter, Lopez, Michel, Libersat and Hammond. This is an open-access article distributed under the terms of the Creative Commons Attribution Non Commercial License, which permits non-commercial use, distribution, and reproduction in other forums, provided the original authors and source are credited. 